\title{
Transforming English Language Education in Saudi Arabia: Why Does Technology Matter?
}

\author{
https://doi.org/10.3991/ijet.v15i06.12655 \\ Saleh Al-Shehri \\ King Khalid University, Abha, Saudi Arabia \\ saleh@kku.edu.sa
}

\begin{abstract}
Several studies have discussed the potential of reforming the Saudi educational system and how to appropriately face and deal with challenges that may hinder this reform in line with Vision 2030. While some studies highlighted factors that can boost this transformation, most reviewed studies proposed futuristic plans of how educational reform can take place in line with Vision 2030. Given that Vision 2030 was just announced around three years ago, and because no clear or accurate indications of its educational paradigm and/or application have yet been made, studies that investigated the Vision's educational opportunities are mostly proposals, meaning that no experimental research has yet been conducted on the actual learning practice, particularly with English education and the incorporation of technology into learning. Thus, the current longitudinal study is an attempt to investigate English language teachers' perceptions of and attitudes about the Vision and whether they have experienced any remarkable educational changes in their own behaviour and teaching practices. The study was conducted with 15 female master's teacher students, with whom two phases of interviews were carried out. The study highlights some educational reform challenges that have or may act as barriers to the achievement of the Vision's goals with regard to English language instruction and the incorporation of technology.
\end{abstract}

Keywords-Education reform, behaviour change, English and technology, Saudi Vision 2030

\section{Introduction}

Since the Saudi government announced its ambitious Vision 2030 in 2016, several studies have discussed the potential of reforming the Saudi educational system and how to appropriately face and deal with challenges that may hinder this reform. While some studies highlighted factors that can boost this transformation, most reviewed studies proposed futuristic plans of how educational reform can take place in line with Vision 2030. Given that Vision 2030 was just announced around three years ago, and because no clear or accurate indications of its educational paradigm and/or application have yet been made, studies that investigated the Vision's educational opportunities are mostly proposals, meaning that no experimental research has yet been conducted 
on the actual learning practice, particularly with English education and the incorporation of technology into learning. Thus, the current longitudinal study is an attempt to investigate English language teachers' perceptions of and attitudes about the Vision and whether they have experienced any remarkable educational changes in their own behavior and teaching practices. The study also highlights some educational reform challenges that have or may act as barriers to the achievement of the Vision's goals with regard to English language instruction and the incorporation of technology.

\section{$2 \quad$ Saudi Education in 2030}

Saudi Vision 2030 has ambitious plans to reform the educational system. The Vision is primarily an attempt to boost the economy and minimize the nation's longstanding dependence on oil as a major source of income. Among the educational goals of the Vision are the following:

- To minimize the gap between tertiary education outcomes and the real needs of local labor markets.

- To position at least five Saudi universities among the top 200 ranked world universities.

- To improve students' achievements to be competitive with world standards.

The Vision does not provide any explicit plans to improve English instruction nor to implement technology. However, better utilization of digital curricula and the introduction of online learning/training platforms are among the interpretations of the Vision's goals. The Vision also indicates that these goals should be achieved through talent improvement and continuous evaluation of learning outcomes throughout all educational stages [1].

Overall, the Vision and previous educational reforms imply a need for flexibility with change. Resistance to change among educators and students, as [2] points out, can be a reflection of the strong conservative and religious traditions of the Saudi community and may hinder the adoption of novel ways of life, including the teaching of English, regardless of the increasing need to teach it for competitive innovation and in light of national reform initiatives.

\section{Saudi English Education in a Globalized World}

The Saudi educational system has undergone several reform projects, particularly beginning with the establishment of the National Center for E-Learning and Distance Learning in 2007 and the Saudi Electronic University in 2011. In addition, most universities launched their own deanships of e-learning as supervisory sectors that manage the introduction of e-curricula and online learning platforms. English instruction found an opportunity for inclusion in these initiatives, and many English teaching practices are now being conducted via online mediums. The introduction of technology into English instruction was meant to improve pedagogical practices in general 
because most students are still teacher-dependent and lack appropriate self-learning skills [3]. Moreover, low achievement and a lack of motivation for learning are common phenomena among the majority of English language students (e.g. $[4,5,6])$. Specifically, English language teachers, as [3] claims, are deemed to be responsible for motivating or demotivating students to learn English. A further complication is that students in an English language learning context lack the opportunity to practice the language in real-life situations. Thus, the introduction of technology is aimed at providing meaningful learning tools and communication channels for a modernized English teaching practice.

\section{English, Technology, and Change: Teachers' Perceptions}

According to [7], student achievement has been widely cited in the literature as a comprehensive term that can stand in for educational reform. However, Burner suggests that the improvement of education rather than achievement is more inclusive because it "better captures the more complex and broader picture of educational instruction than do 'learning' or 'student achievement"' (p. 123). Nonetheless, student achievement is still a major objective for educators and researchers who continue to believe that the level of basic English language skill and language competence among Saudi learners are unsatisfactory and cannot reach the prospects set out in Vision 2030 (see $[8,9,10,11]$ ). However, teachers are the cornerstone of educational change.

A number of studies have explored the perceptions and attitudes of Saudi teachers toward the application of Vision 2030 in the context of teaching English. For example, [12] conducted a study with 50 English language pre-service female teachers and categorized four main characteristics of effective English language teachers in light of Vision 2030. The characteristics included technical knowledge, pedagogical skills, interpersonal skills, and personal qualities. Overall, teacher participants did not consider the incorporation of technology as a sign of quality among English language teachers according to the study, as it did not investigate the potential of technology in achieving the goals of Vision 2030. Another study by [10] explored the role that English language teachers can play in achieving the goals of the Vision. [10] states that the majority of participants had positive attitudes regarding "professional development" in English language programs. The study also indicated that networking with native English language teachers around the world, as well as attending international workshops and conferences in the field, can effectively help Saudi teachers cope with implications of the Vision. Similar to [12] findings, [10] study did not examine the role that technology can play in transforming English language instruction in accordance with the Vision. In contrast, [13] investigated the online competency of a group of teachers working at the Saudi Electronic University. [13] concluded that teachers were keen to effectively integrate technology in appropriate pedagogical approaches. For this reason, improving teachers' Technological Pedagogical and Content Knowledge (TPACK) competence is crucial in helping teachers realize the strategic goals of Vision 2030. 
The status of foreign culture in English language curricula in Saudi Arabia was also investigated by several studies. [14], for instance, explored teachers' experience of developing an English language curriculum and incorporating foreign cultural norms. [14] found that because the educational reform of Vision 2030 is taking place, it is the right time to integrate foreign culture into the English curriculum. Needless to say, technology is bridging the gaps between different cultures and can effectively present cultural norms in English language teaching contexts. In a related study, [3] reviewed some of the research conducted in English language contexts in Saudi Arabia. The study illustrates that most schools lack the appropriate technological tools that could improve the practice of English language instruction. [3] further suggested that teachers should be provided with intensive training on how to implement innovative technology in their teaching practice and that "modern technology must become an integral part of the Saudi EFL classroom to enhance the quality and effectiveness of learning" (p. 115).

Another study, by [15], looked at the changes required to meet the demands of Vision 2030 from teachers' perspective. [15] reviewed relevant studies and analyzed teaching requirements in Saudi public schools, then categorized some of the difficulties that could influence the adoption of educational reform. These difficulties included a lack of motivation among students, the lack of sustainable academic courses, resistance to blended learning among university teachers, and unsatisfactory learning achievements. Most importantly, the analysis indicated that "teachers of English language have a higher level of academic awareness concerning the development of English language teachings to the learners in line with Vision 2030" (p. 114). [16] also implemented a professional development program for teachers using the Substitution, Augmentation, Modification, and Redefinition (SAMR) model, which was aimed at encouraging teachers, including English language teachers, to substitute their traditional teaching methodologies with innovative technology-based methodologies in line with Vision 2030. [16] concluded that teachers' attitudes toward technology were positive in terms of transforming their teaching practice into one that is more student-centered. It was also shown that the model improved teachers' self-efficacy and teaching knowledge for transformative practices.

Teachers' perceptions of the use of tablets in transforming English language instruction was the focus of [17] study. Specifically, the authors identified the advantages and challenges of the use of tablets in English language classrooms in accordance with Vision 2030. Teacher participants stated that tablets can provide students with instructional guidance and modeling, and they can also improve student motivation and collaborative and individual learning. They also noted that tablets can even be used as effective assessment tools. However, teacher concerns over a lack of time to prepare online materials, as well as the lack of appropriate training, were seen as the challenges that may have an impact on the optimal use of tablets in English language classrooms.

The reviewed studies have so far primarily focused on designing instructional proposals that can improve English language education in line with the educational reform strategy of the Vision. While some studies have also looked at the potential of technology to make this transformation vivid and evident, the current study explores 
changes in teachers' perceptions and teaching behaviors over time via a longitudinal research design. Teachers' views on the prospects of the Vision were investigated upon the announcement of the Vision in 2016. Later, another investigation was conducted looking at teachers' perceptions of what progress had been made on each of the Vision goals, based on their teaching experience over the previous 3 years.

\section{Context, Participants, and Data Collection Methods}

The present study was conducted at the College of Education, King Khalid University, Saudi Arabia. Participants in the study were 15 female postgraduate students studying Master of General Curricula and Methodologies, who were all in-service English language teachers with an average of 5 years of teaching experience. They were pursuing their masters as a professional development plan; Saudi teachers with master's qualifications are eligible to be promoted to a higher level.

Before data were collected, participants were asked to learn about the Vision 2030 proposal to improve education in Saudi Arabia. A short video was distributed to all participants along with a link to the official Vision 2030 website, and later, participants were interviewed. The study adopted a longitudinal qualitative design. According to [18], qualitative research methods are often utilized to better understand participants' underlying opinions and behaviors. Participants in the current study were initially interviewed a few months after the announcement of Vision 2030, once they started studying for their master's in late 2016. The first phase of data collection was aimed at exploring participants' views of the Vision and whether English language teachers were ready to adopt such a reform. After completing their coursework study in 2018 and resuming their teaching, participants were again interviewed. This second phase of data collection investigated whether participants' views of the transformative reform had changed after they began teaching again and whether their teaching behavior had changed. Several open questions regarding the status and readiness to change were administered to all participants during the first phase. It should be noted that as male-female face-to-face contact was not yet allowed in the College, interviews were conducted via phone calls. Further clarification and elaboration on certain points were sometimes obtained via email and WhatsApp text messages. For privacy reasons, participants were unwilling to record their phone calls. Thus, notes were taken during the calls. For the second phase of data collection, the same participants were contacted again and asked whether they had experienced any behavioral and/or educational changes in line with the Vision. Participants' perceptions about challenges with the reform were also investigated in the second phase.

Participants were initially asked five major open-ended questions that were intended to raise more discussion points. Distribution of questions over the two phases of data collection followed the Stages of Change Model that describes five stages of readiness developed by [19]. The distribution of the questions according to those five stages is shown in Table 1. 
Table 1. Distribution of research questions in line with the Stages of Change

\begin{tabular}{|l|l|l|}
\hline \multicolumn{1}{|c|}{ Stages of Change } & \multicolumn{1}{|c|}{ Research Questions } \\
\hline Precontemplation & $\begin{array}{l}\text { What would be the benefits of adopting Vision 2030 in Eng- } \\
\text { lish language education? }\end{array}$ \\
\hline Contemplation & $\begin{array}{l}\text { What would be the challenges/concerns of adopting Vision } \\
\text { 2030 in English language education? }\end{array}$ \\
\hline Preparation & $\begin{array}{l}\text { How would you evaluate your own readiness to change in } \\
\text { line with Vision 2030? }\end{array}$ \\
\hline Action & $\begin{array}{l}\text { How can we transform Vision 2030 regarding English lan- } \\
\text { guage education into practical steps? }\end{array}$ \\
\hline Maintenance & $\begin{array}{l}\text { What do you suggest to improve the adoption of Vision 2030 } \\
\text { by English language teachers? What about technology? }\end{array}$ \\
\hline
\end{tabular}

Questions 1,2, and 3 were discussed at the first phase, whereas questions 4 and 5 were discussed at the second phase.

\section{$6 \quad$ Findings}

The perceptions of the participants covered a variety of issues, including their expectations of the benefits of adopting Vision 2030 in English language education, the challenges related to the adoption, teachers' readiness to adopt the change, the move from theory to practice, and suggestions for improvement of the adoption. Findings from the two phases of the study were categorized according to these five issues relevant to the research questions. Additionally, a comparison of the participants' views between the two phases was conducted within the analysis and discussion of each category.

\subsection{Benefits of vision 2030 in English instruction}

A generally positive expectation of the adoption of Vision 2030 in English language education in Saudi Arabia was evident in most comments. For example, one participant pointed out that policy makers are now aware that learning policies can be transformed in order to match global trends in English language education (Participant AQ, 1). Another participant asserted that the Vision calls for immediate adoption of current learning approaches. In her words,

I think it's time to adopt more student-centered approaches in English language learning. Students should be able to choose what is best for their own learning and to choose what fits their abilities and learning styles. (Participant AJ, 1)

Another participant stated that current methodologies are believed to enhance students' critical thinking skills and creativity, which were not evident in the actual learning practice (Participant AS, 1).

As far as language policy was concerned, one participant indicated that while the Vision calls for embracing innovative pedagogical approaches, it highlights the culture and tradition of Saudi society:

What is good about Vision 2030 is that it highly appreciates the local heritage and traditions of our people, and to improve students' self-esteem and pride of 
their own culture in front of the world, while it calls for change and reform. (Participant ZS, 1)

Another participant listed some of the prospects of the Vision and stated that it would allow both policy makers and educators to adopt instructional technology practices from around the world. She noted that English language teachers were reluctant to incorporate foreign culture into their classrooms due to the conservative customs of Saudi society (Participant SS, 1).

At the second phase of the study, it was found that most participants valued the shift they had experienced in their teaching practice that came about in accordance with the Vision. For example, QR codes have been widely incorporated into most textbooks so that students can refer to websites that provide them with additional resources and/or exercises. Some schools and tertiary institutions, one participant mentioned, have started to allow their students to use their mobile phones for both personal and educational purposes (Participant BA, 2). Another participant indicated that some teachers have started to broadly use social media and WhatsApp to collaborate with their students for learning purposes, which is a practice that was limited to university students a few years ago. Moreover, new learning concepts have started to find their way into the teaching experience.

When I resumed teaching after completing my master's study, I noticed that some of my colleagues were talking about new topics that were not there before. They were talking about new concepts that Vision 2030 was propagating, such as sustainability, instructional design, e-tests, virtual learning environments, etc. I think we are taking firm steps toward digital education. (Participant HZ, 2)

\subsection{Challenges of vision 2030 in English instruction}

As with the adoption of any change, participants initially anticipated some challenges that might have an impact on transforming English education. Challenges constituted most of the participants' comments, detailing their concerns over the adoption of the Vision with regard to their prior conceptions about English language education. For example, one participant pointed out that the policy on English language education did not keep pace with current global trends. She added that the qualifications to be an English language teacher, for instance, did not seem to match this promising educational reform and that some of the learning material still adheres to traditional methods.

National transformation asserts a shift toward digital learning practices. However, we noticed from previous plans that this transformation was merely a limited and superficial implementation of technology. This is good, for sure, but we are, rather, still in need of promoting teachers' digital literacy and awareness toward the potential of technology in English language learning. (Participant AJ, 1)

Another participant pointed out that most English language teachers were still utilizing old methodologies that promoted traditional teaching practices such as audiolingual and grammar translation approaches. She further asserted that, with technology, English language teachers should incorporate "perceptual processing strategies" that help students develop audiovisual representations of learning materials (Partici- 
pant $\mathrm{BF}, 1)$. There was also a perception that teachers were still inclined to cover all subjects within the scheduled time regardless of students' understanding or practice enhancement.

Unfortunately, our educational system pays more attention to quantity than quality. It does not consider effective teaching methodologies in an effective way. There are a great deal of subjects and activities that teachers struggle to cover within the time allocated. (Participant $H B, 1$ )

Similarly, another participant commented that obligating teachers to complete all subjects within the dedicated semester time made teaching stressful throughout the semester (Participant RS, 1).

One of the major challenges of the adoption of the Vision, one participant mentioned, was that students were inclined to rely on the teacher for most learning purposes. The lack of appropriate implementation of student-centered learning approaches would require more time and effort for the educational reform to be successful.

Students' full reliance on the teacher has made them less motivated, lazy, and irresponsible, and also made them unable to achieve the learning objectives. (Participant $S G, 1)$

From the participants' overall perspectives, there were other challenges with educational reform, including the inability to cater to students' individual differences due to large class sizes, the unavailability of language learning labs at some schools, or the lack of well-maintained labs, and the inadequacy of teacher training on the use of technology for language learning purposes.

Participants' views obtained during the second phase varied in the ways that their expectations about the advancement in the educational system formed during master's study had not been fully met. In one participant's opinion, students still hold negative attitudes toward English language instruction. Teachers, she added, were still utilizing traditional methods (audio-lingual and grammar translation).

My daughter keeps telling me that she hates English not just because her teacher does not implement engaging strategies or games with students but because instead, she screams most of the time and makes them stressed out. (Participant ES, 2)

Another major challenge to the Vision was the lack of correlation between students' and teachers' digital literacy and awareness. Teachers, for instance, still hold negative attitudes toward the use of tablets or mobile phones in school. In one participant's words,

The teacher is considered as a facilitator of the learning process, and most teachers are now aware of the importance of technology in English learning, but they still consider mobile phones as distracting tools. Teachers also think if mobile phones were widely allowed in classes, students would use them inappropriately, such as for cheating. (Participant $\mathrm{MH}, 2$ )

Other challenges that were still apparent in the educational system, as reflected on by the participants, included students' low motivation, teachers' resistance to the use of technology, a lack of critical thinking and creativity skills in the classroom, and the lack of innovative assessment methods. 


\subsection{Teachers' readiness for change}

Generally positive attitudes about teachers' willingness to adopt the change and take part in the transformative process of the Vision were evident in most participants' comments. One participant, for instance, pointed out that teachers were competing to enroll in professional development programs set by the Ministry of Education. Another participant also asserted that she and some of her colleagues enrolled in different programs covering topics like e-learning, innovative teaching methods, and educational psychology. A participant further advised that pursuing her master's study was part of her personal professional development plans.

As for the second phase of data collection, responses did not differ greatly from those in the first phase. In other words, participants stated that they, as well as most of their colleagues, had enrolled in and/or were applying to enroll in some professional development programs announced by the Ministry. The programs included summer training programs organized by select Saudi universities and Education Departments, and the Program of Qualitative Development (the Khebrat Program).

However, as English language teachers are transferring what they have learned through their experience, teachers' developmental programs should include more technology-based content. One participant wrote,

Emerging developmental programs should incorporate methodologies that focus on the potential of mobile devices in English education and how to effectively and consciously implement them for learning purposes. Teachers should practice using mobile devices in real-life learning situations. (Participant BF, 2)

\subsection{From theory to practice}

Participants were asked whether they have taken definitive action to change their teaching behavior after completing their master's study and returning to their schools, and to what extent they reflect what they learned in their practical teaching experience. As mentioned, participants stated that they had already attended some professional development workshops/conferences organized by the Ministry. Participants considered that to be a developmental strategy that is in line with the Vision. Furthermore, one participant pointed out that she found some of her colleagues had started to think about English language teaching in a different way.

Teachers are now considering professional development a necessity for this era.

They believe that the curriculum is changing dramatically these days, and teachers should cope with this change. They even urge that their own opinions regarding curricular development need to be considered so that resistance to change can be put to the minimum. (Participant AJ, 2)

Another participant expressed that she was astonished by some initiatives taken by her English language teacher colleagues.

When I returned to my school, I found some teachers had incorporated online platforms into their teaching experience, including Google Classroom and Edmodo. I really appreciate how students were interacting via these platforms. They 
were collaborating over different topics beyond the textbooks. They are using them to do their homework and to communicate with their teachers. (Participant AQ, 2)

\subsection{Suggestions for improvement}

Participants reported some recommendations that would improve the practice of English language teaching in Saudi Arabia and would make the change in the education system successful. Participants' most common recommendations can be summarized as the following:

- Current learning strategies, such as personalized learning, self-learning, contextual learning, and critical and creative thinking skills, should be promoted.

- The incorporation of technology for learning purposes should consider students' familiarity with technology and social media and should be implemented in reallife situations. Technology should be utilized because it is effective, not because it is a requirement or because it is already there.

- Students are no longer in need of information; they need to know how to learn better and how to maintain skills needed for future careers.

- Change is about people; both students and teachers should have adequate encouragement, support, and reward throughout the process of learning/teaching transformation. More effective training and professional development plans for teachers should be seriously considered.

- Change and modernity do not imply giving up traditions and cultural norms of the society; religious and national identities should be maintained in a globalized world.

- Professional development programs abroad should allow teachers to realize that their country is opening its doors to the world. Teachers should return to their classrooms more open-minded to new ideas and different views and knowledge. Specifically, English instruction is best incorporated with culture-related activities, which needs to strike a balance between local and foreign cultures.

- Saudi conservative culture treats elderly people with more respect in a way that may create communication barriers between younger and older generations. Therefore, students need to improve their discussion and dialogue skills. Technology can effectively create better teacher-student communication channels and enable students to express themselves freely.

- Teachers' and students' perceptions and attitudes about the transformation of education should be taken into account. The Ministry of Education should conduct periodical large-scale investigations that can improve teaching/learning practices.

- Vision 2030 should consider the improvement of research skills for both students and teachers. Students and teachers can then reflect on educational prospects and challenges, and those reflections should definitely inform the learning design, helping policy makers determine the best scenarios for English language education.

Finally, one perception sums up the recommendations for better education practice: 
Vision 2030 will succeed in reforming education when teachers have reliable values and are proud of their deep-rooted cultural and national identity, when they believe in principles of religious moderation, and when they have adequate knowledge and skills needed for the future. (Participant $M Q, 2)$

\section{$7 \quad$ Discussion and Conclusion}

Time changes the way we teach, and technology has made this educational change a necessity rather than a choice. In his article, "Why is Educational Change so Difficult, and How Can We Make it More Effective?" [7] states that "there are at least three reasons why educational change is necessary: increased globalisation, advancements in technology, and developments in research into teaching and learning approaches" (p. 125). Since change is primarily about changing human behavior, and that change passes through identifiable stages where motivation is a key factor [20], reform in Saudi Arabia is generally intended to happen through rapid operations. In his interview with David Ignatius of the Washington Post, Crown Prince of Saudi Arabia Prince Muhammad bin Salman "described a new wave of reforms as part of the 'shock' therapy needed to modernize the Kingdom's cultural and political life" ([21], para. 1). The "shock" therapy is essential in these circumstances since previous reforms, particularly in the educational system, took longer than expected, cost more than anticipated, and had no satisfactory results. Since 2016, reform plans of Vision 2030 have made tremendous societal, economic, and technological changes in the country. However, the transformation of education requires following a more steady and sometimes cautious path.

Most reviewed studies revealed positive attitudes among Saudi teachers toward embracing change and incorporating innovative technology in their teaching practices (see e.g. [22, 17, 16, 23, 24]). Participants in the current study were initially optimistic about the Vision and how it is going to transform education based on the achievements reach in other sectors. When it comes to actual practice, however, teachers tend to be a bit reluctant for several reasons. For example, some participants expressed their concern over teachers' qualifications and/or adherence to traditional teaching. For example, teacher-centered approaches were still apparent in most English language teaching contexts. Other participants pointed out that the Vision was overly ambitious about incorporating technology to an optimal level; the technological infrastructure at some schools will not provide opportunities for better teaching practices. This is, to some extent, consistent with [25], who describe technology penetration at some rural areas schools as scarce and underfunded. Further, many schools lack modern devices and equipment that would make English instruction more enjoyable and effective [26]. Even most recent studies argue that innovative technology cannot fit well with traditional education "unless proper integration is assured, and infrastructural demands are met" (p. 43) [27]. Thus, most English language teachers, as [28] found, deem themselves in need of good facilities as well as adequate training. This is in line with the current study in the sense that there was a tendency among participants to enroll in professional development programs, either locally or abroad. For 
example, the Khebrat program aims at improving teachers' (particularly English language teachers) English language training, technical skills development, and school immersion. Khebrat is a specialized one-year immersion program run by select international universities, primarily from the United States, the United Kingdom, and Australia. One of the most important objectives of Khebrat, as [29] notes, is to transfer rich teaching experience from well-respected educational institutions into the Kingdom's schools, so that schools can maintain self-efficacy and high-quality standards.

For actual teaching experience, a number of participants indicated that they or some of their colleagues have already incorporated technology into their classrooms. Several reviewed empirical studies also point out that technology has already found its way into actual English language practice (see e.g. [22, 17, 30]). This illustrates that we do not need to worry about the extent to which teachers are implementing technology. Technology is becoming an integral part of almost all Saudi citizens' lives, as it is has existed in most governmental or private daily interactions. The application of e-government functions and procedures at schools and universities has become a common practice in Saudi Arabia. The Ministry of Education, for instance, requires all enrolled students to be registered by their schools through a nationwide electronic system (the Noor System). Students are graded through the system by their teachers, and parents can follow up on their children's performance and achievement. Likewise, teachers are obliged to conduct administrative processes with the Ministry through a number of online platforms. Hence, in addition to their personal use of technology, it can be argued that Saudi teacher's master good digital literacy, and they would then not find it frustrating to integrate technology into their teaching practice. [31] (para. 5) demonstrate the current status of internet and technology use in Saudi Arabia:

Saudi Arabia has the largest social media presence in the world. With 43.80 million mobile subscribers, mobile penetration stands at $129 \%$ of the total population. The major reason for the high number of active social media users is due to the high rate of smartphone ownership. With more than $84 \%$ of the country living in urbanized areas with super-fast internet connections, it comes as no surprise that the active social media users stand at 23 million, an incredible $67.95 \%$ of the population.

Suggestions of participants for improving teaching practice were generally reflected in some studies that examined teachers' perceptions of English education and technology incorporation, as well as perceptions of Vision 2030. For example, [10] investigated the contribution of English language teachers in fulfilling the educational objectives of the Vision. According to [10], 95\% of teachers emphasized that knowledge and experience exchange between teachers from around the world is a crucial professional development strategy. Additionally, Twitter was the most preferred tool for some teachers to communicate and collaborate with their international counterparts. Similarly, [11] stated that few conceptions in her study had as much interest expressed as pursuing further study in English-speaking countries. Likewise, [12] found that over $80 \%$ of interviewed teachers noted that keeping up with conferences and workshop attendance were necessary to improve their English teaching practice. This is consistent with the large proportion of responses perceiving that teaching practices 
were in need of promoting current learning practices such as personalized learning and self-learning.

As far as cultural incorporation was concerned, a number of participants expressed their concerns over the incorporation of foreign culture in their classroom practices. Similarly, other participants assured that English language education should be aligned with the promotion of religious and national values of the Saudi community. This is in line with findings from [14] study, in which English language teachers were reluctant to incorporate foreign cultural norms into classroom practices. However, cultural sensitivity in most English language teaching contexts, [14] argues, entails a widespread argument that makes it hard to determine what is appropriate and what is inappropriate for today's students. This is true since a language cannot be isolated from its own cultural norms. Additionally, there is no contradiction between foreign and local cultures when it comes to learning other nations' customs and traditions. Moreover, today, students are immersed in different social media platforms and are living in a media-rich globalized world. Technology-based learning approaches, as [32] point out, can promote students' engagement and "can help overcome past issues of stereotyping and lack of intercultural awareness" (p. 75). Hence, it seems unjustifiable not to integrate foreign cultural norms that do not contradict with Saudi culture.

While more research conducted with larger-sized samples of participants is needed to explore areas beyond perceptions analyzed and discussed in the current study, the results provide insights into current practices of English language instruction in Saudi Arabia. It further investigates teachers' preparedness and readiness to shift their teaching experiences into innovative ones that can consolidate the national educational gains of Vision 2030. Greater attention should be paid to the pedagogical and technological behavior of both teachers and students and to what extent technology implemented inside and outside of classrooms is educationally effective. Teachers' change is a prerequisite of student change; therefore, changed teachers would help students to become "more critically reflective, and to integrate meaning perspectives that are more integrative of experience" (p. 408) [33]. Future research needs to identify ways to improve teacher-student communication and promote collaboration channels. We also need to know how to exploit students' literacy and familiarity with current technology for learning purposes. We still also need to know how to narrow the gap between teachers' and students' digital literacy. Evidence obtained from future research will inform English language instruction in Saudi Arabia and provide insightful feedback as to what progress has been made on each of Vision 2030's educational goals.

\section{$8 \quad$ References}

[1] Vision 2030, 2017. [Online], Available: http://vision2030.gov.sa/download/file/fid/422 [Accessed: July 14, 2019].

[2] T. M. Al-Saraj, "Foreign language anxiety in female Arabs learning English: Case studies," Innovation in Language Learning and Teaching, vol. 8, no. 3, pp. 257-278, 2014. https://doi.org/10.1080/17501229.2013.837911 
[3] F. Alrabai, "Learning English in Saudi Arabia," in English as a foreign language in Saudi Arabia: New insights into teaching and learning English, C. Moskovsky and M. Picard, Eds. London: Routledge, 2018, pp. 102-119. https://doi.org/10.4324/9781315688466-5

[4] M. Alrahaili, "Predictors of L2 attitudes and motivational intensity: A cross-sectional study in the Saudi EFL context," PhD dissertation, The University of Newcastle, Newcastle, Australia, 2014.

[5] O. Alrashidi and H. Phan, "Education context and English teaching and learning in the Kingdom of Saudi Arabia: An overview," English Language Teaching, vol. 8, no. 5, pp. 33-44, 2015. https://doi.org/10.5539/elt.v8n5p33

[6] T. Elyas and M. Picard, "Saudi Arabian educational history: Impacts on English language teaching," Education, Business and Community: Contemporary Middle Eastern Issues, vol. 3, no. 2, pp. 136-145, 2010. https://doi.org/10.1108/17537981011047961

[7] T. Burner, "Why is educational change so difficult and how can we make it more effective?," Forskning og Forandring, vol. 1, no. 1, pp. 122-134, 2018. https://doi.org/10.2386 $\underline{\text { 5/fof.v1.1081 }}$

[8] A. Alsudais, "Teaching English as a foreign language: The case of Saudi Arabia," European Journal of English Language and Literature Studies, vol. 5, no. 9, pp. 18-27, 2017.

[9] H. A. Alyami, "Future plan to improve education in the Kingdom of Saudi Arabia in light of the Kingdom's 2030 Vision," Arab Journal of Sciences \& Research Publishing, vol. 26, no. 2, pp. 32-49, 2018.

[10] N. O. Al-Zahrani, "The role of English language teachers in achieving the Kingdom's 2030 Vision," Arab Journal of Sciences \& Research Publishing, vol. 1, no. 1, pp. 111-126, 2017.

[11] E. Asiri, "Saudi English teachers' beliefs and values towards English language teaching in Saudi Arabia,” M. S. thesis, Indiana University of Pennsylvania, Indiana, PA, 2017.

[12] A. T. Shawaqfeh, "Characteristics of effective English language teachers in the light of Saudi Arabia's 2030 Vision," Umm Al-Qura University Journal of Educational \& Psychological Sciences, vol. 9, no. 2, pp. 9-30, 2018.

[13] A. Albuloushi, "Investigating the relation between Saudi teachers' self-perceptions of TPACK and their practical application in lesson design," PhD dissertation, Duquesne University, Pittsburgh, PA, 2019.

[14] B. Alamri, "Foreign culture in English curriculum in Saudi Arabia: A teacher's voice," Arab World English Journal, Special Issue 1: Application of Global ELT Practices in Saudi Arabia, pp. 34-41, 2019. https://doi.org/10.24093/awej/elt1.3

[15] N. Yusuf, "Changes required in Saudi universities curriculum to meet the demands of 2030 Vision," International Journal of Economics and Finance, vol. 9, no. 9, pp. 111-116, 2017. https://doi.org/10.5539/ijef.v9n9p111

[16] T. Aldosemani, "Inservice teachers' perceptions of a professional development plan based on SAMR Model: A case study," The Turkish Online Journal of Educational Technology, vol. 18 , no. 3, pp. 46-53, 2019.

[17] W. S. Albiladi and K. K. Alshareef, "The use of tablets in teaching English in Saudi Arabia: Implications and challenges," International Journal of English and Education, vol. 7, no. 3, pp. 281-294, 2018.

[18] J. W. Creswell, Research design: Qualitative, quantitative, and mixed methods approaches. Thousand Oaks, CA: SAGE, 2014. https://doi.org/10.5539/elt.v12n5p40

[19] C. C. DiClemente and J. Prochaska, "Toward a comprehensive transtheoretical model of change: Stages of change and addictive behaviors," in Treating addictive behaviour, W. R. Miller and N. Heather, Eds. New York: Plenum, 1998, pp. 3-24. https://doi.org/10.1007/9 78-1-4899-1934-2 1 
[20] G. L. Zimmerman, C. G. Olsen, and M. F. Bosworth, "A 'stages of change' approach to helping patients with change behaviour," American Family Physician, vol. 61, no. 5, 1409$16,2000$.

[21] D. Ignatius, "The crown prince of Saudi Arabia is giving his country shock therapy," The Washington Post, para. 1, Feb. 28, 2018. [Online], Available: https://www.washingt onpost.com/opinions/the-crown-prince-of-saudi-arabia-is-giving-his-country-shock-therap $\mathrm{y} / 2018 / 02 / 27 / \mathrm{fd} 575 \mathrm{e} 2 \mathrm{e}-1 \mathrm{bf0}-11 \mathrm{e} 8-9 \mathrm{de} 1-147 \mathrm{dd} 2 \mathrm{df3} 329$ story.html [Accessed Oct. 12, 2019]. https://doi.org/10.1108/oxan-db239527

[22] K. M. Alabsi, and F. M. A. Alghamdi, "Students' opinions on the functions and usefulness of communication on WhatsApp in the EFL higher education context," Arab World English Journal, Special Issue 1: Application of Global ELT Practices in Saudi Arabia, pp. 129-144, 2019. https://doi.org/10.24093/awej/elt1.10

[23] N. O. A. Al-Zahrani and H. Rajab, "Attitudes and perceptions of Saudi EFL teachers in implementing Kingdom of Saudi Arabia's Vision 2030," International Journal of English Language Education, vol. 5, no. 1, pp. 83-99, 2017. https://doi.org/10.5296/ijele.v5i1.1073 $\underline{3}$

[24] A. Basabrin, A. "Exploring EFL Instructors and students perceptions of written corrective feedback on Blackboard platform: A case study," Arab World English Journal, Special Issue 1: Application of Global ELT Practices in Saudi Arabia, pp. 179-192, 2019. https://doi.org/10.2139/ssrn.3472204

[25] N. Saqlain, F. Al-Qarni, and N. Ghadi, "Are English language teachers in Saudi Arabia ready to integrate technology?," Procedia - Social and Behavioral Sciences, vol. 103, pp. 146-153, 2013. https://doi.org/10.1016/j.sbspro.2013.10.319

[26] A. S. Al-Nasser, "Problems of English language acquisition in Saudi Arabia: An exploratory-cum-remedial study," Theory and Practice in Language Studies, vol. 5, no. 8, pp. 1612-1619, 2015. https://doi.org/10.17507/tpls.0508.10

[27] H. A. Albazie, "Advantages and challenges of integrating m-learning into Saudi Arabian universities: A literature review," European Journal of Open Education and E-learning Studies, vol. 3, no. 1, pp. 35-46, 2018.

[28] B. Mitchell and A. Alfuraih, "English language teaching in the Kingdom of Saudi Arabia: Past, present and beyond," Mediterranean Journal of Social Sciences, vol. 8, no. 2, pp. 317-325, 2017. https://doi.org/10.5901/mjss.2017.v8n2p317

[29] M. Alabdali, " 8 objectives provided by Khebrat in 9 countries around the world," Alwatan Saudi Newspaper, para. 4, July 22, 2018. [Online], Available: https://www.alwatan.

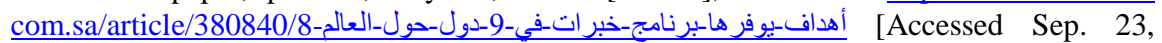
2019].

[30] S. Eldeeb, “An investigation into students' views on blended learning at the English Language Institute in King Abdulaziz University," Arab World English Journal, Special Issue 1: Application of Global ELT Practices in Saudi Arabia, pp. 164-178., 2019. https://doi. org/10.2139/ssrn. 3472203

[31] Global Media Insight, "Saudi Arabia Social Media Statistics," Global Media Insight, Oct. 29, 2019. [Online], Available: https://www.globalmediainsight.com/blog/saudi-arabiasocial-media-statistics/ [Accessed: Nov. 8, 2019].

[32] O. Dema and A. J. Moeller, A. J. "Teaching culture in the 21 st century language classroom," Faculty Publications: Department of Teaching, Learning and Teacher Education, vol. 181, pp. 75-91, 2012.

[33] M. J. Moore, "The transtheoretical model of the stages of change and the phases of transformative learning: Comparing two theories of transformational change," Journal of Trans- 
formative Education, vol. 3, no. 4, pp. 394-415, 2005. https://doi.org/10.1177/1541344605 $\underline{279386}$

\section{Author}

Saleh Al-Shehri is an Assistant Professor of TESOL and Mobile Learning at College of Education, King Khalid University, Saudi Arabia. His research interests include English language learning and technology, teachers' and students' behavior, mobile learning, and connectivism. E-mail: saleh@kku.edu.sa.

Article submitted 2019-12-08. Resubmitted 2019-12-27. Final acceptance 2019-12-28. Final version published as submitted by the authors. 